\title{
In Situ Preparation of Titanium Carbide Ceramic Layer on Grey Cast Iron
}

\section{Lisheng ZHONG ${ }^{1,2}$, Tiandong WU ${ }^{2}$, Xi ZHANG ${ }^{1}$, Shaozhong FAN ${ }^{3}$, Liangliang WANG ${ }^{3}$, Shili CHEN $^{3}$}

\author{
${ }^{1}$ School of Materials Science \& Engineering, Xi'an University of Technology, Xian 710048, China \\ ${ }^{2}$ School of Materials Science \& Engineering, Northwestern Polytechnical University, Xi'an 710068, China \\ ${ }^{3}$ Institute of Wear Resistant Materials, Xi'an University of Architecture \& Technology, Xi'an 710055, China \\ cross $^{\text {ref }}$ http://dx.doi.org/10.5755/j01.ms.21.4.9700
}

Received 28 January 2015; accepted 11 September 2015

\begin{abstract}
In this article, we report the in situ synthesis of $\mathrm{TiC}$ ceramic layer between titanium plate and graphite phases in grey cast iron using heat treatment method. The microstructure of the compound region was characterized by X-ray diffraction (XRD) and scanning electron microscopy (SEM), and the kinetics of the TiC ceramic layer was analyzed. The results revealed that the as-prepared TiC samples were irregularly shaped particles with a size of $1 \sim 8 \mu \mathrm{m}$ and gradient distribution on the surface of grey cast iron. The thickness of the reaction layers increased gradually as the incubation continued, which were $62,81,95$ and $108 \mu \mathrm{m}$ after incubation at $1164{ }^{\circ} \mathrm{C}$ for $1,2,3$ and 4 hours, respectively. Also, it can be recognized that the layer thickness changes in a parabolic style with incubation duration. The formation process of TiC ceramic layer consists of diffusion and in situ reaction of carbon and titanium atoms.

Keywords: TiC, ceramic, in-situ reaction, microstructure, kinetics.
\end{abstract}

\section{INTRODUCTION}

Metal-based composites reinforced by ceramic particles have become a novel class of advanced materials that are widely applied in inexpensive wear resistant parts. Therefore, these materials have been intensively investigated during the past three decades [1]. The composites offer various advantages such as costeffectiveness, good wear resistance, excellent mechanical properties, etc.

Titanium carbide (TiC) reinforced iron surface composite, which can provide great wear resistance for the substrate in a variety of working conditions, has gained increasing attention and become one of the hottest topics in the field of surface composites [2-4]. TiC with a Vickers hardness of $2895 \sim 3200 \mathrm{HV}$ is one of the most promising reinforcing agents for the iron and steel matrix due to its availability, high melting point, high hardness and good thermodynamic stability. Most importantly, the TiC can be chemically wetted by the iron matrix. It has been shown that the wetting angle $(\theta)$ between $\mathrm{TiC}$ and molten iron is less than $50^{\circ}$, even at elevated temperatures or with pressure [5-6].

Methods that are commonly employed for the preparation of the $\mathrm{TiC}$ particle reinforced iron-based surface composite include accelerated electron beam irradiation [5, 7], GTAW multi-layers melting process [8], self-sustaining high-temperature synthesis (SHS) [6] and surface alloying using laser cladding [9]. However, these methods show several drawbacks such as imperfect surface quality, low precision, high content of gas, porosity and slag inclusion, resulting in limited capability of fabricating components with complex geometry, etc.

\footnotetext{
* Corresponding author. Tel.: +86-29-82312107; fax: +86-29-82312107.

E-mail address: zhonglisheng@nwpu.edu.cn (L. Zhong)
}

In situ reaction technology has been considered as one of the most promising methods for the preparation of ironbased composites in virtue of the fine size and thermodynamic stability of the ceramic particulates in the matrix and a strong interfacial bonding between the reinforcing agents and the matrix. In this article, an in situ process was developed for the fabrication of $\mathrm{TiC}$ ceramic layer on grey cast iron matrix and the phase evolution and microstructures were studied. One of the most promising advantages of the proposed process is the metallurgical bonding between ceramic layer and matrix as a result of in situ reaction. Other advantages include low cost, facile process and simple equipment.

\section{EXPERIMENTAL DETAILS}

For the in situ fabrication of $\mathrm{TiC}$ ceramic layer on grey cast iron, grey cast iron (HT 300) and titanium plates (thickness $=0.125 \mathrm{~mm}$ and purity $=99.779 \%$ ) were employed as carbon and titanium sources, respectively. The chemical composition of grey cast iron (wt.\%) was: 3.45 C, 0.56 Si, 0.27 Mn, 0.224 P, 0.024 S.

Fig. 1 is a schematic diagram showing the fabrication procedures of $\mathrm{TiC}$ ceramic layer on grey cast iron. A grey cast iron block with a cube shape $(10 \mathrm{~mm} \times 10 \mathrm{~mm} \times 10 \mathrm{~mm})$ was prepared. The titanium plate $(10 \mathrm{~mm} \times 10 \mathrm{~mm} \times 0.125 \mathrm{~mm})$ was fixed to the cube. Afterwards, the specimen was heated to $1200{ }^{\circ} \mathrm{C}$ and kept for $20 \mathrm{~min}$, followed by incubation at $1160{ }^{\circ} \mathrm{C}$, an appropriate temperature that was chosen based on the partial dissolution temperature of the titanium plate determined by differential scanning calorimetry (DSC) [10]. The specimen was subjected to heat treatment at $1160{ }^{\circ} \mathrm{C}$ for different dwelling times $(1,2,3$, and 4 hours) in a horizontal tube furnace with a modest flow of argon and cooled down to room temperature naturally. 


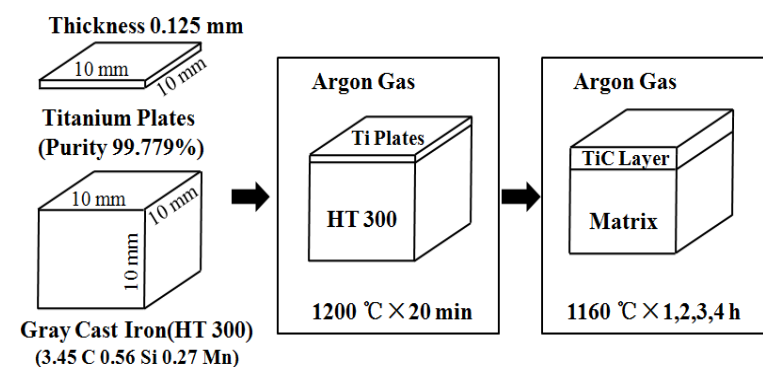

Fig. 1. Schematic diagram of fabrication procedures of $\mathrm{TiC}$ ceramic layer on grey cast iron

After polishing with diamond paste and etching with a $4 \%$ Nital solution, the as-prepared specimens were characterized by scanning electron microscope (SEM; EVO-18 ZEISS, Germany). Then, the specimen was characterized by X-ray diffraction (XRD; PW 1730 Philips, The Netherlands) with monochromated $\mathrm{Cu} K_{\alpha}$ radiation at $40 \mathrm{kV}$ and $40 \mathrm{~mA}$ in the $2 \theta$ range of $10 \sim 90^{\circ}$.

\section{RESULTS AND DISCUSSION}

\subsection{Microstructure and phases}

Fig. 2 shows the SEM micrographs of the reaction layer between the titanium plate and matrix after heat treatment at $1200{ }^{\circ} \mathrm{C}$ for $20 \mathrm{~min}$. The melting-point of the grey cast iron is about $1150 \sim 1200{ }^{\circ} \mathrm{C}$, according to the $\mathrm{Fe}-\mathrm{C}$ equilibrium phase diagram. As a result, the grey cast iron surface was melted, and the reaction layer between the titanium plate and matrix was in form of particles. Despite of the minor variations, thickness of the reaction layer was approximately $25 \mu \mathrm{m}$. The interface between the reaction layer and the matrix was clear and visible. Due to the cracks occurred in the interface of the reaction layer and the cast iron, the bonding strength between reaction layer and cast iron was lowered.

Fig. 3 shows the SEM micrographs of the microstructures of the reaction layers after heat treatment at $1160{ }^{\circ} \mathrm{C}$ for different times. The thickness of the reaction layers, which were $62,81,95$ and $108 \mu \mathrm{m}$ for holding 1, 2, 3 and 4 hours, respectively, gradually increased with the incubation duration. The reaction layers were composed of dense particles and the density of the layers did not show significant change as the incubation continued. Besides, a significant change was observed in the microstructure of grey cast iron matrix. The graphite flakes in grey cast iron were consumed, leading to a mixture of pearlite and ferrite for the microstructure.

Phases presented in the reaction layer were characterized by X-ray diffraction and the result is shown

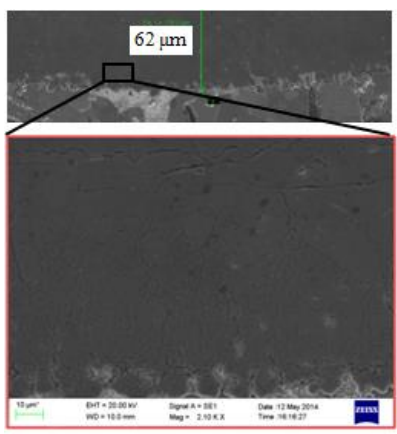

$\mathrm{a}-1160^{\circ} \mathrm{C} \times 1 \mathrm{~h}$
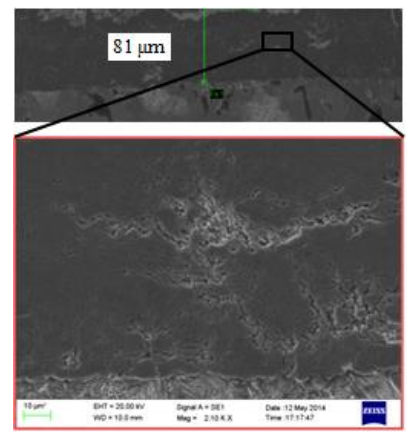

$\mathrm{b}-1160^{\circ} \mathrm{C} \times 2 \mathrm{~h}$ $\mathrm{c}-1160^{\circ} \mathrm{C} \times 3 \mathrm{~h}$

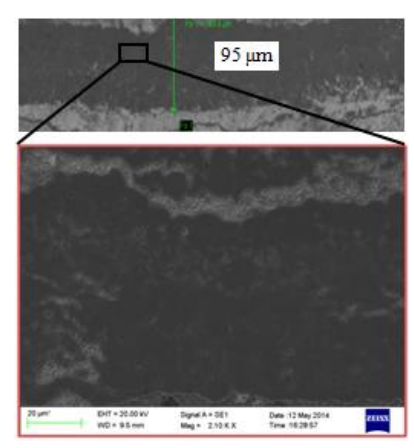

in Fig. 4. The XRD patterns of the reaction layer on grey cast iron were measured by taking the cross section of the sample as an example. In the specimen heat treated at $1160{ }^{\circ} \mathrm{C}$ for 4 hours, peaks of $\alpha-\mathrm{Fe}, \mathrm{TiC}$ and graphite can be observed. Here, high $\alpha$-Fe peaks indicate a large content of ferrite in the matrix and a small amount of graphite. Dense particles found in the specimens were identified as TiC. It can be concluded that the $\mathrm{TiC}$ particles were synthesized in situ between the titanium in titanium plate and the carbon in the graphite flakes. As the graphite flakes were consumed, and the matrix microstructure transferred to ferritic phase with graphite. Also, it's worth noting that no obvious pearlitic characteristic peaks are observed, while the reasons need further clarification.

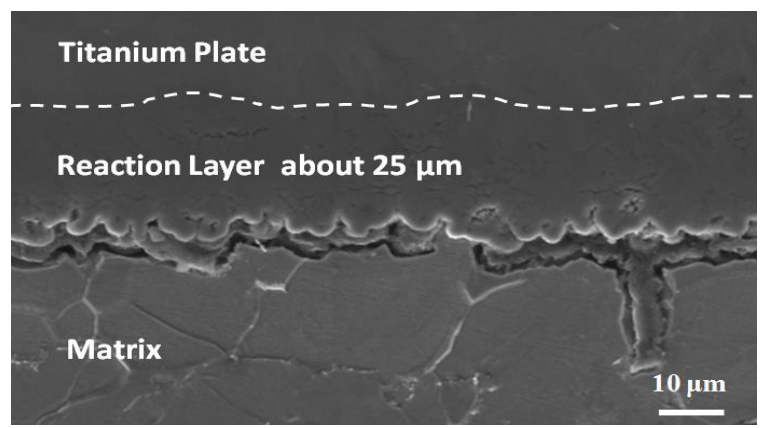

Fig. 2. SEM micrographs of the reaction layer between titanium plate and grey cast iron matrix after heat treatment at $1200{ }^{\circ} \mathrm{C}$ for $20 \mathrm{~min}$

The reaction on the titanium plate was realized by the heat diffusion of carbon and titanium atoms. The original interface between the titanium plate and the grey cast iron was eliminated while no defects were resulted. An Image Statistical Analysis about all the distribution of the dimensions in the different zones was performed [11]. The particle size after $4 \mathrm{~h}$ was also obtained by the Image Statistical Analysis. The TiC particles synthesized in situ are irregularly shaped, with a size of $1 \sim 8 \mu \mathrm{m}$ and gradient distribution on the surface of grey cast iron. Additionally, the size of TiC particles increased from the interface to the composite surface, while pearlite and ferrite could be observed at the vicinity of the reaction boundary. From what has been discussed above, the titanium carbide ceramic layer on grey cast iron, which was prepared by in situ, has several characteristics. Firstly, the thickness of the titanium carbide ceramic layer on grey cast iron is $25 \sim 108 \mu \mathrm{m}$, and the distribution of TiC particles on the matrix is dense and the density of the layer did not show significant change with the different times.

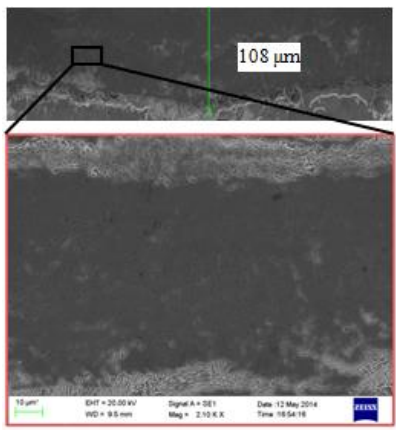

$\mathrm{d}-1160^{\circ} \mathrm{C} \times 4 \mathrm{~h}$

Fig. 3. SEM micrographs showing the overall microstructures of the reaction layers after heat treatment at $1160{ }^{\circ} \mathrm{C}$ for different times 
Secondly, the titanium carbide particle size is $1 \sim 8 \mu \mathrm{m}$ and it increased from the interface to the surface. Thirdly, the micro-hardness of the titanium carbide ceramic layer is about $1400 \mathrm{HV}_{0.05}$, and shows excellent wear resistance. Sahoo C. K. et al [12] produced $\mathrm{TiC}$ reinforced steel composite layer by laser scanning over the preplaced $\mathrm{TiC}$ powder on AISI 304 steel substrate. The thickness of the composite layer was about $150 \mu \mathrm{m}$, and the particle size of $\mathrm{TiC}$ is $10 \sim 14 \mu \mathrm{m}$. The distribution of $\mathrm{TiC}$ particle is uneven, and the volume fraction of particle is lower. Beside, the micro-hardness of the layer is $800 \sim 1200 \mathrm{HV}_{0.05}$ with different process, while the value in our study is about $1400 \mathrm{HV}_{0.05}$ due to higher $\mathrm{TiC}$ volume fraction. Emamian A. et al [13] prepared Fe-TiC composite coating on AISI 1030 carbon steel by laser cladding. Dendritic TiC distributed in iron matrix, and the volume fraction of $\mathrm{TiC}$ is only $20 \sim 33 \%$, and the particle size is $2 \sim 10 \mu \mathrm{m}$, which is similar to our work. Onuoha C. C. et al [14] developed a family of nove TiC-304L stainless steel composite. The cermets exhibit high hardness, which increase with $\mathrm{TiC}$ content, exhibiting a maximum value in excess of $\sim 2500 \mathrm{HV}_{1}$ with just $5 \%$ steel binder content. The TiC particle size is about $7 \mu \mathrm{m}$, and volume fraction is $70 \sim 95 \%$, which is the reason to excellent wear resistance.

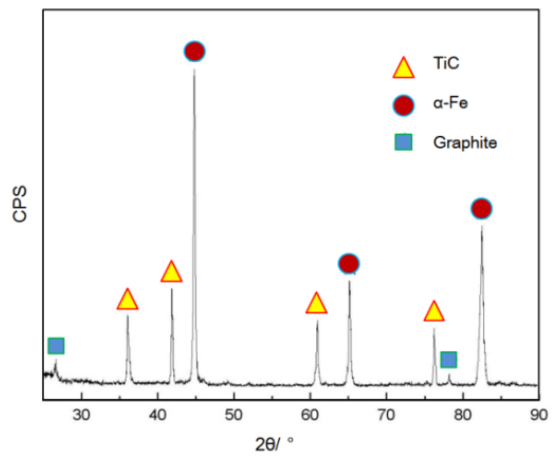

Fig. 4. XRD pattern of the specimen heat treated at $1160{ }^{\circ} \mathrm{C}$ for $4 \mathrm{~h}$ after heating at $1200{ }^{\circ} \mathrm{C}$ for $20 \mathrm{~min}$

\subsection{Kinetics of the $\mathrm{TiC}$ ceramic layer}

The thickness of the $\mathrm{TiC}$ ceramic layer fabricated in situ depends on heat incubation temperature and duration. The classic relation between thickness of reaction layer $(d)$ and heat treatment time $(t)$ is:

$d=K t^{0.5}+b_{0}$,

where $b_{0}$ is the initial thickness of the reaction layer and $K$ is the growth rate constant depending on the processing temperature. The correlation between growth rate constant
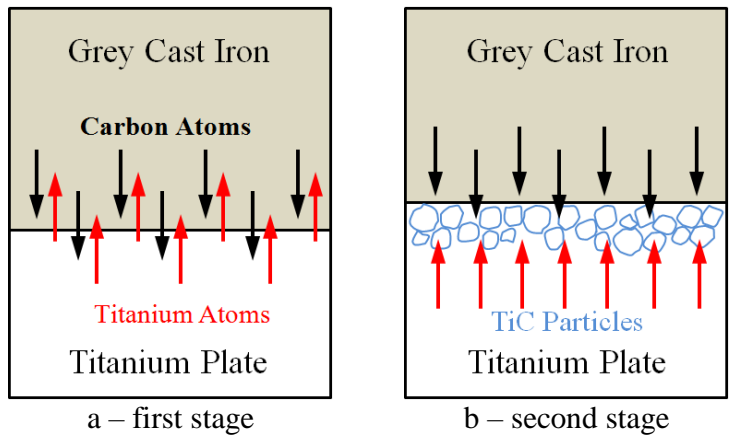

$(K)$ and processing temperature $(T)$ can be expressed by an Arrhenius equation ${ }^{[15]}$ as follows:

$K=K_{0} \exp \left(-\frac{Q}{R T}\right)$,

where $K_{0}$ is a pre-exponential constant, $Q$ is the activation energy $\left(\mathrm{J} \cdot \mathrm{mol}^{-1}\right)$ and $R$ is the gas constant $\left(\mathrm{J} \cdot \mathrm{mol}^{-1} \mathrm{~K}^{-1}\right)$.

If the kinetics of $\mathrm{TiC}$ layer progress for the periods between 1 and 4 hours is considered, it can also be recognized that the layer thickness changed in a parabolic style with time as seen in Fig. 5. Calculated $K$ values derived from the slopes of the plots of the $\mathrm{TiC}$ layer treatment were $6.61 \times 10^{-7} \mathrm{~m} \cdot \mathrm{s}^{-0.5}$ at a processing temperature of $1160{ }^{\circ} \mathrm{C}$.

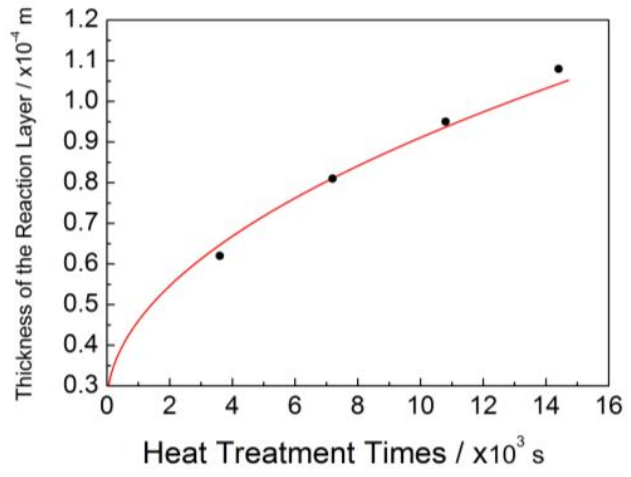

Fig. 5. Thickness of the reaction layer with different heat treatment times

\subsection{Formation process of $\mathrm{TiC}$ ceramic layer}

Based on the microstructure and kinetics process, a schematic diagram of $\mathrm{TiC}$ ceramic layer on grey cast iron was depicted, as shown in Fig. 6. The formation of $\mathrm{TiC}$ ceramic layer consists of diffusion and in situ reaction of carbon and titanium atoms and the whole process may be divided into three main stages:

First stage: Metallurgical bonding between titanium plate and grey cast iron (heat treatment at $1200{ }^{\circ} \mathrm{C}$ for $20 \mathrm{~min}$ ). Due to the good wettability, titanium plate and grey cast iron is metallurgically bonded at a heat treatment temperature is $1200{ }^{\circ} \mathrm{C}$. On one hand, solid solution of titanium diffused into the ferrite in the form of displacement solution at temperatures above the austenitizing temperature. On the other hand, carbon atoms were extracted from graphite flakes at $1200{ }^{\circ} \mathrm{C}$. In consequence, concentration gradients of titanium atoms and carbon atoms were observed at the interface between titanium plate and grey cast iron (Fig. 6 a).
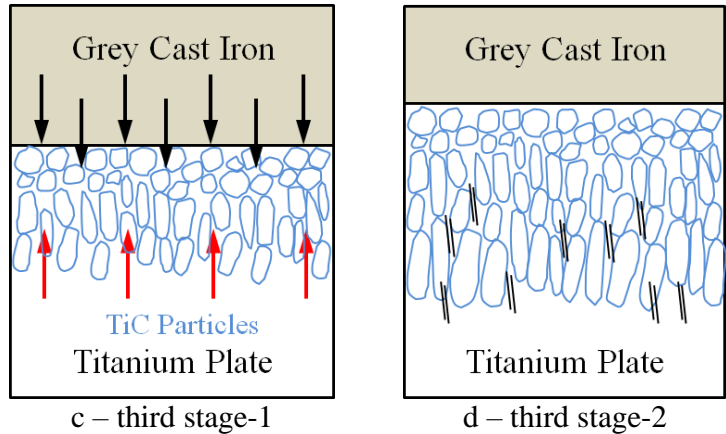

Fig. 6. Reaction process model of the $\mathrm{TiC}$ ceramic layer on grey cast iron 
Second stage: Formation of small TiC particles. Carbon atoms in the grey cast iron were interstitial ones due to their small atomic radii and the diffusion rate was high. It diffused to the interface firstly, followed by reaction with titanium solid solution in ferrite as follow:

$[\mathrm{C}]+[\mathrm{Ti}] \rightarrow[\mathrm{TiC}]$

$[\mathrm{TiC}] \rightarrow \mathrm{TiC}$,

where Eq. 3 is the in situ reaction process, and Eq. 4 is the nucleation process of TiC. Due to the large quantity of nuclei formed, the reaction system was dominated by particle nucleation. Moreover, the growth of $\mathrm{TiC}$ grain was inhibited by the high atomic concentration of carbon. Therefore, the grain size of $\mathrm{TiC}$ at this stage was relatively small (Fig. 6 b).

Third stage: Formation of big size $\mathrm{TiC}$ particle and diffusion of $\mathrm{TiC}$. After heat treatment at $1200{ }^{\circ} \mathrm{C}$ for $20 \mathrm{~min}$, heat incubation temperature was reduced to $1160{ }^{\circ} \mathrm{C}$, and the grey cast iron was in molten state. The diffusion rate decreased due to the formation of $\mathrm{TiC}$ reaction layer. Meanwhile, titanium plate and grey cast iron were segregated by the reaction layer, and the solid solution of titanium into the ferrite was interdicted. Concentrations of carbon and titanium atoms at the interface decreased drastically and the particle size of $\mathrm{TiC}$ increased because of the reduced inhibitory effect from carbon atomic concentration (Fig. 6 c). After heating halting, unreacted carbon atoms in the matrix transform to cementite, and microstructure of the matrix are pearlite and ferritic (Fig. $6 \mathrm{~d}$ ).

In summary, the forming process of $\mathrm{TiC}$ layer can be simplified as "diffusion and in situ reaction", including transportation of carbon atoms to the reaction sites by diffusion and synthesis of $\mathrm{TiC}$ by in situ reaction.

\section{CONCLUSIONS}

Using a novel in situ process, the synthesis of a $\mathrm{TiC}$ ceramic layer on grey cast iron can be facile. The synthesized TiC was irregularly shaped particles with a size of $1 \sim 8 \mu \mathrm{m}$ and gradient distribution on the surface of grey cast iron. The thickness of the reaction layers increased gradually with the holding times. Also, it can be recognized that the layer thickness changed in a parabolic style with times. The formation process of $\mathrm{TiC}$ ceramic layer consists of diffusion and in situ reaction of carbon and titanium atoms.

\section{Acknowledgments}

The project supported by Postdoctoral Science Foundation of China (grant no. 2014M552488) and the National High Technology Research and Development Program of China (grant no. 2013AA031803). The authors also acknowledge the financial support from the International S \& T Cooperation Program of China (grant no. 2014DFR50630), the Doctoral Scientific Research Foundation of Xi'an University of Technology (grant no. 101-451115013), the National Natural Science Foundation of China (grant no. 51501148), and the Project of the Shaanxi Key Laboratory of Nano Materials and Technology (grant no. 15JS054, 14JS046, and 13JS053).

\section{REFERENCES}

1. Liu, J., Li, J., Xu, C. Interaction of the Cutting Tools and the Ceramic-reinforced Metal Matrix Composites During Micro-machining: A Review CIRP Journal of Manufacturing Science and Technology 7 2014: pp. 55-70. http://dx.doi.org/10.1016/j.cirpj.2014.01.003

2. Chen, X., Zhai, H., Wang, W., Li, S., Huang, Z. A $\mathrm{TiC}_{x}$ Reinforced $\mathrm{Fe}(\mathrm{Al})$ Matrix Composite Using In Situ Reaction Progress in Natural Science Materials International 23 2013: pp. $13-17$.

http://dx.doi.org/10.1016/j.pnsc.2013.01.002

3. Feng, K., Yang, Y., Shen, B.L., Guo, L. In Situ Synthesis of $\mathrm{TiC} / \mathrm{Fe}$ Composites by Reaction Casting Materials \& Design 26 2005: pp. 37-40.

4. Wang, J., Wang, Y. In-situ Production of Fe-TiC Composite Materials Letters 61 2007: pp. 4393-4395. http://dx.doi.org/10.1016/j.matlet.2007.02.011

5. Lee, J., Euh, K., Oh, J.C., Lee, S. Microstructure and Hardness Improvement of TiC/stainless Steel Surface Composites Fabricated by High-energy Electron Beam Irradiation Materials Science and Engineering A 323 2002: pp. 251-259.

6. Persson, P., Jarfors, A.E.W., Savage, S. Self-propagating High-temperature Synthesis and Liquid-phase Sintering of $\mathrm{TiC} / \mathrm{Fe}$ Composites Journal of Materials Processing Technology 127 2002: pp. 131-139.

http://dx.doi.org/10.1016/S0924-0136(02)00113-9

7. Lee, J., Euh, K., Lee, S. Microstructural Analysis of TiC Reinforced Ferrous Surface Composites Processed by Accelerated Electron Beam Irradiation Current Applied Physics 1 2001: pp. 467-471.

8. Wang, X.H., Song, S.L., Zou, Z.D. Fabricating TiC Particles Reinforced Fe-based Composite Coatings Produced by GTAW Multi-layers Melting Process Materials Science and Engineering A 441 2006: pp. 60-67. http://dx.doi.org/10.1016/j.msea.2006.06.015

9. Li, J., Luo, X., Li, G.J. Effect of $\mathrm{Y}_{2} \mathrm{O}_{3}$ on the Sliding Wear Resistance of TiB/TiC-reinforced Composite Coatings Fabricated by Laser Cladding Wear 310 2014: pp. $72-82$. http://dx.doi.org/10.1007/s10853-010-5157-1

10. Zhong, L.S., Xu, Y.H., Liu, X.J., Ye, F.X. Study on NbC Particulate-reinforced Iron Matrix Composite Produced In Situ Journal of Materials Science 46 2011: pp. $2814-2819$. http://dx.doi.org/10.1007/s10853-010-5157-1

11. Wang, L.L., Xu, Y.H., Zhong, L.S. Abrasive Wear Characteristics of In-situ TiC-reinforced Iron Matrix Surface Gradient Composites Advanced Materials Research 535-537 2012: pp. 81-85.

12. Sahoo, C.K., Masanta, M. Effect of Pulse Laser Parameters on TiC Reinforced AISI 304 Stainless Steel Composite Coating by Laser Surface Engineering Process Optics and Lasers in Engineering 67 2015: pp. 36-48.

13. Emamian, A., Alimardani, M., Khajepour, A. Correlation Between Temperature Distribution and In Situ Formed Microstructure of Fe-TiC Deposited on Carbon Steel Using Laser Cladding Applied Surface Science 258 2012: pp. $9025-9031$.

14. Onuoha, C.C., Kipouros, G.J., Farhat, Z.N., Plucknett, K.P. The Reciprocating Wear Behavior of TiC-304L Stainless Steel Composites Prepared by Melt Infiltration Wear 303 2013: pp. $321-333$.

15. Kim, J.H., Kim, S.Y., Kang, C.Y. Effect of Phase Difference on Growth Kinetic of Alloy Layer in Aluminized and Diffusion-treated $12 \%$ Cr Heating Resistant Steels Surface and Coatings Technology 240 2014: pp. 387-392. http://dx.doi.org/10.1016/j.surfcoat.2013.12.061 